\title{
Sexual dimorphism in neonates and maternal stature at term pregnancy predispose delivery outcomes: Considering predilection of spontaneous vaginal delivery for healthy pregnancies in Nigeria
}

\author{
Godwin Chinedu Uzomba ( $\sim$ uzombagodwinchinedu@yahoo.com ) \\ Alex Ekwueme Federal University Ndufu Alike \\ Uchenn Kenneth Ezemagu \\ Alex Ekwueme Federal University Ndufu Alike \\ Chukwuemeka Ubochi \\ Alex Ekwueme Federal University Ndufu Alike \\ Rachel Ogbu \\ Alex Ekwueme Federal University Ndufu Alike \\ Augustine Oseloka lbegbu \\ Alex Ekwueme Federal University Ndufu Alike \\ Friday Chibuzor Egba \\ Alex Ekweme Federal Teaching University Hospital, Abakaliki \\ Olisa Onuora \\ Alex Ekweme Federal Teaching University Hospital, Abakaliki \\ Paul Olisaemeka Ezeonu \\ Alex Ekweme Federal Teaching University Hospital, Abakaliki \\ Thecla Ezeonu \\ Alex Ekweme Federal Teaching University Hospital, Abakaliki
}

\section{Research Article}

Keywords: Apgar score, Cesarean section, Fetal macrosomia, Birth protocol, Vagina

Posted Date: February 16th, 2022

DOI: https://doi.org/10.21203/rs.3.rs-1259429/v1

License: (a) (1) This work is licensed under a Creative Commons Attribution 4.0 International License. Read Full License 


\section{Abstract}

Objectives: We aim to develop a labor protocol for male or female birth, base on maternal and neonatal stature.

Materials and method: A prospective study of a cross section of pregnant mothers and their newborn babies, based on convenient sampling technique. A total of 480 mothers that were identified by a gynecologist as having healthy pregnancies and their newborn babies in gynecology ward of Alex Ekwueme Federal University Teaching Hospital Abakaliki, Nigeria, from $1^{\text {st }}$ July to $1^{\text {st }}$ December, 2019 volunteered to participate in this study. Maternal and neonatal anthropometries; weight, height, BMI, waist girth (WG), hip girth (HG), birth head girth (BHG), and delivery outcomes: mode of delivery and duration of first and second stages of labor, and Apgar score at 1 minute of birth were considered. We adopted the guidelines of Institute of Medicine for direct anthropometric measurements.

Results: The study recorded low prevalence of cesarean deliveries and abnormal apgar score.

Male birth weight was dependent on maternal age, weight and HG $(P<0.05)$. Birth weight and length, WG and HG could predict mode of delivery of male birth. Maternal and birth anthropometric features could not predict the duration of first stage of labor, but maternal age, $\mathrm{BMI}, \mathrm{HG}$ and percentage body fat could determine that of second stage for female birth. Apgar score was dependent on birth weight and mode of delivery and duration of second stage of labor.

Conclusions: The study reveals that maternal and male birth features tend to be similar, and relatively large maternal waist-hip ratio and fetal macrosomia at term pregnancy could be risk factors of male birth through vagina. Advance age of mothers in pregnancy and overweight and large WHR could be responsible for prolong labor, which leads to abnormal Apgar score. Relatively young expectant mothers with normal BMI and WHR could be granted more time during second stage of labor, since it could enhance the Apgar score of female birth. The study provided a comprehensible means to enable the gynecologists and midwives advice expectant mothers on possible risk of birth through vagina, with respect to her baby's sex and her belief or cultural obligations.

\section{Introduction}

Attempts to circumvent undesirable birth outcomes through spontaneous vaginal delivery in low risk pregnancies have remained a global concern till date. In our locality, expectant mothers prefer to visit birth attendants to maternity clinic, and few visit conventional hospitals during complicated labor. Sometimes, it is usually difficult for the gynecologist to talk into a mother with healthy pregnancy, the husband or next of kin to approve cesarean section, even when labor is prolong [1]. A detailed obstetrics and gynecology protocol considering how maternal and birth features interfere with delivery outcomes could alter the cultural perceptions and disbelief of Cesarean deliveries [2,3]. It should serve to assess and reduce the possibility of undesirable outcomes for birth through vagina, such as still birth, maternal morbidity and mortality during child birth. Birth outcomes are dependent on new born size and maternal stature [4,5,6] and genetic, racial, biological and environmental factors [7,8,9], and nutrition, psychosocial stress, malaria and socio-demographic factors [10].

Noteworthy, failure to understand the pattern of sexual dimorphism in birth features and its role in birth dynamics may lead to poor prognosis and diagnosis of severe complications that may arise during pregnancy and child birth. Such complications include; intrauterine growth retardation and congenital anomalies [11,12], and mechanically obstructed labor due to Cephalopelvic disproportion and Macrosomia [4,13,14]. Recently, there are substantive evidences to suggest a relationship between duration of stages of labor and cervical dilatation patterns. Labor induction and augmentation with Oxytocin and epidural anesthesia are now commonly practiced over instrumental and vaginal breech deliveries [15]. In obstetrics, the size of fetal head and how it adapts with maternal bony pelvis is an essential feature of labor [16].

According to Nigeria Demographic and Health Survey, 36\% of women have their deliveries at home or with traditional birth attendants. Consequently, the neonatal mortality rate in Ebonyi state stood at 35\% with more male death than that of female [17]. Approximately, in four million global neonatal deaths that occur annually, $98 \%$ occur in developing countries, while they are being cared for by mothers, relatives, and traditional birth attendants at home [18]. Attempts to improve birth outcomes of a male child are highly commendable, considering the death rate and cultural expectations in our locality. Male fetus grows faster than female in the early stage of gestation [19], and mean birth weight for male babies are more than that of females in Indonesia [20]. There is a gender difference in skin folds of full-term Nigerian neonates [21]. Therefore there is need to understand the peculiarity of a male or female birth dynamics and develop a gender specific protocol, accordingly. 
The study aims to correlate maternal stature at term pregnancy and that of her newborn with mode of delivery and duration of first and second stages of labor and Apgar score at 1 minute of birth. Second, it aims to ascertain how each of the anthropometric features affects a male or female birth, considering the fact that women with healthy pregnancies in our locality attempt spontaneous vaginal birth first, but go for Caesarean birth when it fails. The result of this research would help to forecast the possibility of a rapid or mechanically obstructed labor and need for early intervention. It will also provide a data base that will enhance the existing obstetrics and gynecology protocol for women in labor as this is first study of its kind in Nigeria.

\section{Materials And Methods Participants}

It was a cross sectional, population study base on convenient sampling technique, which was carried out among pregnant mothers and their newborn babies in gynecology ward of AEFUTHA from $1^{\text {st }}$ July to $1^{\text {st }}$ December, 2019. A total of 480 mothers that were identified by the gynecologist as having low risks of undesirable birth outcome volunteered to participate in this study, but 177 were considered. Three hundred and three mothers with multiple pregnancies, congenital deformities, still birth and underlying cases such as pre-eclampsia were excluded in line with the purpose of the study. Each subject voluntarily signed a consent form, which was read in her preferred local dialect. The study was approved by the Research and Ethics Committee of AEFUTHA, with a reference number: AE-

FUTHA/REC/VOL2/2019/213.

\section{Methods}

Anthropometric data of the mothers with gestational age (range; $38,40 \mathrm{wks}$ ) were collected through direct standard measurements. The reliability and accuracy of the weighing scale was assessed before commencement of measurement. Maternal anthropometries were measured in labor room, which provided an appreciable privacy. Standing in erect position on a health scale (model RGZ-160, England) without support, and looking at Frankfurt plane, their weight and height were recorded to the nearest $0.1 \mathrm{~kg}$ and $0.1 \mathrm{~cm}$, respectively, as adopted by Goon et al. ${ }^{19}$. According to World Health Organization cut-off points, BMI was calculated as Weight/Height ${ }^{2}\left(\mathrm{~kg} / \mathrm{m}^{2}\right)$ and categorized as follows; underweight $\left(<18.5 \mathrm{~kg} / \mathrm{m}^{2}\right)$, normal $\left(18.5-24.9 \mathrm{~kg} / \mathrm{m}^{2}\right)$, overweight $\left(25.0-29 \mathrm{~kg} / \mathrm{m}^{2}\right)$ and obese $\left(\geq 30 \mathrm{~kg} / \mathrm{m}^{2}\right)$ $[18,23]$. Waist girth (WG) of each subject was measured at midpoint between inferior margin of the lowest palpable rib and top of the iliac crest. Hip girth $(\mathrm{HG})$ was measured at the widest circumference over the buttocks, with the tape parallel to the floor. For both measurements, the subject was made to stand erect and relaxed. The measurements were taken at end of a normal expiration to nearest $0.1 \mathrm{~cm}$, using a stretch-resistant tape [24]. We adopted Michelli's method to calculate percentage body fat of each mother [25]. The measurement of birth weight, length and head circumference were done within $1 \mathrm{hr}$ of birth, using standard criteria as described in studies [26,27]. Birth weight was measured and recorded to nearest $0.1 \mathrm{~kg}$, using infant weighing scale (Bassinet: model 180). Birth length and head circumference were recorded to nearest $0.1 \mathrm{~cm}$, using a stretch-resistant tape. The measurement of each parameter was repeated twice and when the difference was within $1 \mathrm{~cm}$, the average was considered. The delivery outcomes such as birth weight, mode of delivery (spontaneous vaginal and Cesarean) and duration of $1^{\text {st }}$ and $2^{\text {nd }}$ stages of labor and Apgar score at 1 minute of birth were recorded in a standard form used in obstetrics by two research assistants that are qualified nurses trained in midwifery. The data were thoroughly rechecked for errors, daily, by the authors; a gynecologist/pediatrician and the lead investigator.

\section{Data analyses}

The differences in anthropometric parameters of maternal, male and female births were tested using two sample t-tests (Table 1). The relationship between maternal and neonatal anthropometries and duration of labor (Table 2), were tested using Pearson correlation coefficient. Regression analyses were performed to substantiate the effects of maternal and neonatal anthropometries on mode of delivery (Table 3) and duration of labor (Table 4 \& 5), and Apgar score at 1 minute of birth (Table 6). The association between Apgar score and mode of delivery and duration of stages of labor were tested (Table $7 \& 8$ ). $P$ value $<0.05$ was considered to be statistically significant. Figure 1 shows the frequency distribution (\%) of Male and Female birth weight categories and mode of delivery. The data were cleaned using Microsoft excels and then exported to SPSS version 23 (SPSS Inc. Chicago, IL) for analyses and results as shown in Table $1-8$ and figure 1.

\section{Results}


The two sample t-test in Table 1 shows no significant mean difference between male and female birth parameters $(P>0.05)$. Table 2 shows that variation in male birth weight could depend on maternal age, weight and HG. The birth length of both sexes correlated with maternal weight, height, WG and HG. The duration of first stage of labor for a male birth could depend on maternal weight and height. Table 3 shows that maternal WHR; WG and HG and birth weight and length could predict mode of delivery of male birth. None of the maternal and birth anthropometric features could independently predict the duration of first stage of labor for male and female births (Table 4). Table 5 shows that duration of second stage of labor of male birth was not dependent on maternal and neonatal anthropometric features while that of female birth was dependent on maternal age, BMI, HG and percentage body fat. Table 6 shows that birth weight could predict Apgar score, but specifically, WG could predict Apgar score of male birth. Table 7 shows a significant association between Apgar score and mode of deliveries of male and female neonates $(P<0.05)$. Table 8 shows significant relationship between second stage of labor and apgar score of female newborn, ( $p>0.05)$. Figure 1 shows low prevalence of cesarean deliveries and abnormal apgar score. Summary of the results was shown in table $1-8$ and fig. 1, below.

Table 1

Descriptive and t-test Statistics of Mothers with Male and Female births and Duration of Labor and Neonatal Anthropometries at AEFUTHA, Nigeria

\begin{tabular}{|c|c|c|c|c|c|c|c|c|}
\hline \multirow[t]{2}{*}{ Variables } & & \multicolumn{3}{|l|}{ Male } & \multicolumn{3}{|l|}{ Female } & \multirow{2}{*}{$\begin{array}{l}\mathrm{p} \text { - } \\
\text { value }\end{array}$} \\
\hline & & Mean \pm SD & Min. & Max. & Mean $\pm S D$ & Min. & Max. & \\
\hline \multirow[t]{8}{*}{ Maternal } & Age (years) & $30.45 \pm 4.53$ & 21.00 & 42.00 & $29.44 \pm 4.18$ & 17.00 & 40.00 & 0.125 \\
\hline & Weight (kg) & $74.92 \pm 11.07$ & 50.00 & 100.10 & $75.29 \pm 11.21$ & 51.00 & 96.00 & 0.826 \\
\hline & Height (m) & $1.63 \pm 0.25$ & 1.00 & 2.00 & $1.61 \pm 0.11$ & 1.20 & 1.76 & 0.489 \\
\hline & BMI $\left(\mathrm{kg} / \mathrm{m}^{2}\right)$ & $28.78 \pm 3.89$ & 18.50 & 38.27 & $29.03 \pm 3.82$ & 17.65 & 42.36 & 0.669 \\
\hline & $\begin{array}{l}\text { Waist circumference } \\
\text { (cm) }\end{array}$ & $103.75 \pm 11.45$ & 70.00 & 118.60 & $104.98 \pm 12.08$ & 71.00 & 133.00 & 0.489 \\
\hline & Hip circumference $(\mathrm{cm})$ & $95.77 \pm 10.28$ & 70.00 & 114.00 & $97.85 \pm 11.15$ & 65.00 & 116.50 & 0.201 \\
\hline & WHR & $1.07 \pm 0.06$ & 1.00 & 1.21 & $1.07 \pm 0.05$ & 1.01 & 1.30 & 0.941 \\
\hline & Body fat (\%) & $33.66 \pm 7.62$ & 12.00 & 46.92 & $36.23 \pm 4.65$ & 23.14 & 51.87 & 0.007 \\
\hline \multirow[t]{5}{*}{ Neonatal } & Birth weight (g) & $3195.18 \pm 522.87$ & 1900.00 & 5000.00 & $3091.49 \pm 429.22$ & 1400.00 & 4200.00 & 0.200 \\
\hline & Birth length (cm) & $44.70 \pm 9.97$ & 35.00 & 59.00 & $46.23 \pm 4.55$ & 31.00 & 53.00 & 0.622 \\
\hline & $\begin{array}{l}\text { Head circumference } \\
(\mathrm{cm})\end{array}$ & $35.71 \pm 2.12$ & 24.00 & 39.00 & $34.95 \pm 4.07$ & 18.75 & 35.26 & 0.714 \\
\hline & First stage of labor (hr) & $14.18 \pm 1.96$ & 10.00 & 18.00 & $13.71 \pm 2.00$ & 10.00 & 18.00 & 0.130 \\
\hline & $\begin{array}{l}\text { Second stage of labor } \\
\text { (hr) }\end{array}$ & $0.47 \pm 0.12$ & 0.30 & 1.00 & $0.46 \pm 0.12$ & 0.30 & 1.00 & 0.387 \\
\hline
\end{tabular}

Table 1 shows significant difference ( $p>0.05)$ of percentage body fat between mothers that give birth to male and female neonates but not with other variables $(p<0.05)$. While no significant mean difference between the variables for sexes $(P<0.05)$

Table 2

Pearson Correlation Coefficients of Maternal and Neonatal Anthropometries and Duration of Labor at AEFUTHA, Nigeria 


\begin{tabular}{|c|c|c|c|c|c|c|c|c|c|}
\hline variables & & $\begin{array}{l}\text { Age } \\
\text { (years) }\end{array}$ & $\begin{array}{l}\text { Weight } \\
(\mathrm{kg})\end{array}$ & $\begin{array}{l}\text { Height } \\
(\mathrm{m})\end{array}$ & $\begin{array}{l}\text { BMI } \\
\left(\mathrm{kg} / \mathrm{m}^{2}\right)\end{array}$ & $\begin{array}{l}\text { Waist } \\
\text { Circumference } \\
(\mathrm{cm})\end{array}$ & $\begin{array}{l}\text { Hip } \\
\text { circumference } \\
(\mathrm{cm})\end{array}$ & WHR & $\begin{array}{l}\% \text { Body } \\
\text { fat }\end{array}$ \\
\hline \multirow{5}{*}{$\begin{array}{l}\text { Male } \\
\text { birth }\end{array}$} & Weight (g) & $0.320 * \star$ & $0.279 *$ & 0.110 & 0.213 & 0.207 & $0.234^{*}$ & -0.033 & 0.135 \\
\hline & Length (cm) & 0.130 & 0.540 ** & $0.445^{\star}$ & $0.243^{*}$ & $0.60 * \star$ & $0.473^{*}$ & $0.225^{\star}$ & 0.528 ** \\
\hline & $\begin{array}{l}\text { Head } \\
\text { Circumference } \\
(\mathrm{cm})\end{array}$ & 0.003 & 0.020 & -0.142 & 0.128 & -0.097 & -0.094 & 0.001 & -0.100 \\
\hline & $\begin{array}{l}\text { First stage of } \\
\text { labor (hr) }\end{array}$ & -0.014 & 0.220 * & $0.284^{\star \star}$ & -0.003 & -0.187 & 0.148 & 0.109 & 0.045 \\
\hline & $\begin{array}{l}\text { Second stage of } \\
\text { labor (hr) }\end{array}$ & 0.152 & -0.093 & 0.017 & -0.126 & -0.036 & -0.092 & 0.043 & -0.078 \\
\hline \multirow{5}{*}{$\begin{array}{l}\text { Female } \\
\text { birth }\end{array}$} & Weight (g) & -0.041 & 0.096 & -0.048 & 0.173 & 0.034 & -0.043 & 0.193 & 0.174 \\
\hline & Length (cm) & 0.041 & $0.482^{\star}$ & $0.538 * \star$ & -0.048 & 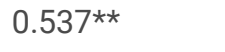 & $0.482^{\star \star}$ & 0.156 & -0.041 \\
\hline & $\begin{array}{l}\text { Head } \\
\text { Circumference } \\
(\mathrm{cm})\end{array}$ & 0.111 & -0.046 & -0.148 & 0.100 & -0.013 & -0.025 & 0.032 & 0.118 \\
\hline & $\begin{array}{l}\text { First stage of } \\
\text { labor (hr) }\end{array}$ & -0.175 & -0.038 & 0.082 & -0.115 & 0.025 & 0.047 & -0.076 & -0.144 \\
\hline & $\begin{array}{l}\text { Second stage of } \\
\text { labor (hr) }\end{array}$ & 0.167 & -0.160 & -0.062 & -0.095 & -0.109 & -0.120 & -0.009 & -0.060 \\
\hline
\end{tabular}

*. **Correlation is significant when $P<0.05$ and 0.001 (2-tailed), respectively.

Table 2 shows that variation in male birth weight was dependent on maternal age, weight and hip circumference. Male and female birth lengths were dependent on maternal weight, height, waist and hip circumference. The duration of first stage of labor for a male birth was dependent on maternal weight and height.

Table 3

Logistics Regression of Maternal Anthropometries with Mode of Delivery of Male or Female Births at AEFUTHA 


\begin{tabular}{|c|c|c|c|c|c|c|c|c|}
\hline Anthropometric Parameters & Mode & Delivery & & & & & & \\
\hline & Male & & & & Female & & & \\
\hline Maternal Parameters & $\mathrm{B}$ & Sig & OR & Nagelkerke R Square & $\mathrm{B}$ & Sig & OR & Nagelkerke R Square \\
\hline Age (years) & -0.137 & 0.142 & 0.872 & & -0.072 & 0.829 & 0.930 & \\
\hline Weight (kg) & -0.030 & 0.763 & 0.971 & & -0.007 & 0.976 & 0.993 & \\
\hline Height (m) & -5.084 & 0.124 & 0.006 & & 3.615 & 0.867 & 0.372 & \\
\hline BMI $\left(\mathrm{kg} / \mathrm{m}^{2}\right)$ & 0.023 & 0.929 & 1.023 & 0.471 & 0.118 & 0.949 & 1.125 & 0.072 \\
\hline Waist circumference $(\mathrm{cm})$ & -0.778 & 0.041 & 0.460 & & 0.245 & 0.618 & 1.278 & \\
\hline Hip circumference (cm) & -0.801 & 0.036 & 2.228 & & -0.283 & 0.596 & 0.754 & \\
\hline WHR & 0.840 & 0.016 & 0.303 & & -19.669 & 0.688 & 0.001 & \\
\hline Body fat (\%) & -0.125 & 0.405 & 0.882 & & 0.062 & 0.965 & 1.064 & \\
\hline Neonatal Parameters & & & & & & & & \\
\hline Weight (g) & -0.001 & 0.012 & 0.999 & & 0.000 & 0.657 & 1.000 & \\
\hline Length (cm) & -0.191 & 0.020 & 0.826 & & 0.029 & 0.752 & 1.029 & \\
\hline Head circumference (cm) & -0.367 & 0.060 & 0.692 & & 0.109 & 0.520 & 1.116 & \\
\hline
\end{tabular}

Table 3 shows that maternal WHR; waist and hip circumference and birth weight and length could predict mode of delivery of male birth.

Table 4

Linear Regression of Maternal anthropometry features with duration of first stage of labor on sex of neonates at AEFUTHA 


\begin{tabular}{|c|c|c|c|c|c|c|c|c|c|c|c|}
\hline \multicolumn{2}{|c|}{$\begin{array}{l}\text { Anthropometric } \\
\text { Parameters }\end{array}$} & \multicolumn{10}{|c|}{ Duration first stage of labor } \\
\hline & & \multicolumn{5}{|l|}{ Male } & \multicolumn{5}{|l|}{ Female } \\
\hline & & $\mathrm{B}$ & Sig & $\begin{array}{l}95 \% \mathrm{Cl} \\
\text { upper lin }\end{array}$ & $\begin{array}{l}\text { wer- } \\
\text { t) }\end{array}$ & $\begin{array}{l}\text { Adjusted } \\
\text { R square }\end{array}$ & B & Sig & $\begin{array}{l}95 \% \mathrm{CI}(\mathrm{I} \\
\text { upper lim }\end{array}$ & $\begin{array}{l}\text { wer- } \\
\text { t) }\end{array}$ & $\begin{array}{l}\text { Adjusted } \\
\text { R square }\end{array}$ \\
\hline \multirow[t]{8}{*}{ Maternal } & Age (years) & -0.067 & 0.546 & -0.287 & 0.153 & \multirow{11}{*}{0.075} & -0.213 & 0.183 & -0.528 & 0.102 & \multirow{11}{*}{0.106} \\
\hline & Weight (kg) & 0.023 & 0.853 & -0.219 & 0.265 & & 0.123 & 0.270 & -0.097 & 0.343 & \\
\hline & Height (m) & 1.333 & 0.673 & -4.926 & 7.591 & & -18.017 & 0.108 & -40.058 & 4.023 & \\
\hline & $\mathrm{BMI}\left(\mathrm{kg} / \mathrm{m}^{2}\right)$ & 0.056 & 0.852 & -0.537 & 0.648 & & -1.100 & 0.205 & -2.814 & 0.614 & \\
\hline & $\begin{array}{l}\text { Waist } \\
\text { circumference } \\
(\mathrm{cm})\end{array}$ & 0.253 & 0.196 & -0.134 & 0.641 & & -0.162 & 0.618 & -0.803 & 0.480 & \\
\hline & $\begin{array}{l}\text { Hip } \\
\text { circumference } \\
(\mathrm{cm})\end{array}$ & -0.313 & 0.318 & -0.729 & 0.103 & & 0.228 & 0.513 & -0.462 & 0.919 & \\
\hline & WHR & -12.781 & 0.513 & -52.513 & 25.951 & & 2.209 & 0.496 & -4.380 & 8.797 & \\
\hline & Body fat (\%) & -0.062 & 0.704 & -0.389 & 0.264 & & 0.552 & 0.411 & -0.775 & 1.878 & \\
\hline \multirow[t]{3}{*}{ Newborn } & Weight (g) & 0.001 & 0.255 & 0.000 & 0.001 & & 0.553 & 0.803 & 0.001 & 0.003 & \\
\hline & Length (cm) & 0.185 & 0.206 & -0.104 & 0.474 & & 0.057 & 0.524 & -0.119 & 0.232 & \\
\hline & $\begin{array}{l}\text { Head } \\
\text { Circumference } \\
(\mathrm{cm})\end{array}$ & -0.231 & 0.464 & -0.856 & 0.394 & & 0.113 & 0.334 & -0.118 & 0.345 & \\
\hline
\end{tabular}

Table 4 shows that duration of first stage of labor for male and female births was not dependent on maternal and neonatal anthropometric features.

Table 5

Linear Regression of Maternal anthropometry features with duration of second stage of labor on sex of neonates at AE-FUTHA 


\begin{tabular}{|c|c|c|c|c|c|c|c|c|c|c|c|}
\hline \multicolumn{2}{|c|}{ Maternal parameters } & \multicolumn{10}{|c|}{ Duration of second stage of labor } \\
\hline & & \multicolumn{5}{|l|}{ Male } & \multicolumn{5}{|c|}{ Female } \\
\hline & \multirow[b]{2}{*}{ Age (years) } & \multirow{2}{*}{$\begin{array}{l}\text { B } \\
0.005\end{array}$} & \multirow{2}{*}{$\begin{array}{l}\text { Sig } \\
0.159\end{array}$} & \multicolumn{2}{|c|}{$\begin{array}{l}95 \% \mathrm{Cl} \text { (lower- } \\
\text { upper limit) }\end{array}$} & \multirow[t]{2}{*}{$\begin{array}{l}\text { Adjusted } \\
\text { R square }\end{array}$} & \multirow{2}{*}{$\begin{array}{l}\text { B } \\
0.041\end{array}$} & \multirow{2}{*}{$\begin{array}{l}\text { Sig } \\
0.013\end{array}$} & \multicolumn{2}{|c|}{$\begin{array}{l}95 \% \mathrm{Cl} \text { (lower- } \\
\text { upper limit) }\end{array}$} & \multirow[t]{2}{*}{$\begin{array}{l}\text { Adjusted } \\
\text { R square }\end{array}$} \\
\hline & & & & -0.002 & 0.011 & & & & 0.009 & 0.073 & \\
\hline & Weight (kg) & 0.003 & 0.432 & -0.004 & 0.010 & & -0.011 & 0.346 & -0.034 & 0.012 & \\
\hline & Height (m) & -0.105 & 0.267 & -0.291 & 0.082 & & 2.005 & 0.087 & -0.296 & 4.305 & \\
\hline & $\mathrm{BMI}\left(\mathrm{kg} / \mathrm{m}^{2}\right)$ & -0.013 & 0.161 & -0.030 & 0.005 & & 0.235 & 0.009 & 0.061 & 0.409 & \\
\hline \multirow{4}{*}{ Maternal } & $\begin{array}{l}\text { Waist } \\
\text { circumference } \\
(\mathrm{cm})\end{array}$ & 0.005 & 0.371 & -0.006 & 0.017 & & 0.061 & 0.067 & -0.004 & 0.126 & \\
\hline & $\begin{array}{l}\text { Hip } \\
\text { circumference } \\
(\mathrm{cm})\end{array}$ & -0.006 & 0.321 & -0.019 & -0.006 & \multirow{3}{*}{0.076} & -0.075 & 0.037 & -0.145 & -0.005 & \multirow[t]{3}{*}{0.195} \\
\hline & WHR & -0.529 & 0.365 & -1.684 & -0.626 & & -5.900 & 0.077 & -12.446 & 0.647 & \\
\hline & Body fat (\%) & 0.001 & 0.940 & -0.009 & -0.010 & & -0.158 & 0.022 & -0.293 & -0.024 & \\
\hline \multirow[t]{3}{*}{ Neonatal } & Weight (g) & -7.480 & 0.552 & 0.001 & 0.002 & & 0.202 & 0.593 & -0.548 & 0.951 & \\
\hline & Length (cm) & 0.004 & 0.398 & -0.005 & 0.012 & & -0.030 & 0.566 & -0.133 & 0.073 & \\
\hline & $\begin{array}{l}\text { Head } \\
\text { Circumference } \\
(\mathrm{cm})\end{array}$ & -0.013 & 0.170 & -0.133 & 0.073 & & 0.006 & 0.730 & -0.030 & 0.043 & \\
\hline
\end{tabular}

Table 5 shows that maternal and neonatal anthropometric features could not predict significantly, duration of second stage of labor of male birth but maternal age, BMI, hip circumference and percentage body fat could for female birth.

Table 6

Logistics regression of maternal and neonatal anthropometric features with Apgar score of male and female births at AEFUTHA 


\begin{tabular}{|c|c|c|c|c|c|c|c|c|}
\hline \multirow{2}{*}{$\begin{array}{l}\text { Anthropometric } \\
\text { Parameters }\end{array}$} & \multicolumn{7}{|c|}{ Apgar score } & \multirow[b]{3}{*}{$\begin{array}{l}\text { Nagelkerke R } \\
\text { Square }\end{array}$} \\
\hline & Male & & & & Female & & & \\
\hline Maternal Parameters & B & Sig & OR & $\begin{array}{l}\text { Nagelkerke R } \\
\text { Square }\end{array}$ & $\mathrm{B}$ & Sig & OR & \\
\hline Age (years) & 0.104 & 0.564 & 1.109 & \multirow{12}{*}{0.465} & 0.398 & 0.076 & 1.489 & \multirow{12}{*}{0.211} \\
\hline Weight (kg) & 0.074 & 0.597 & 1.077 & & -0.023 & 0.938 & 0.977 & \\
\hline Height (m) & 1.725 & 0.621 & 5.612 & & 2.977 & 0.920 & 19.625 & \\
\hline $\mathrm{BMI}\left(\mathrm{kg} / \mathrm{m}^{2}\right)$ & -0.510 & 0.222 & 0.600 & & 1.288 & 0.354 & 3.627 & \\
\hline Waist circumference (cm) & -0.405 & 0.036 & 0.667 & & 0.355 & 0.536 & 1.426 & \\
\hline Hip circumference $(\mathrm{cm})$ & 0.289 & 0.142 & 1.335 & & -0.336 & 0.590 & 0.715 & \\
\hline WHR & 11.021 & 0.636 & 0.611 & & -43.569 & 0.440 & 0.001 & \\
\hline Body fat (\%) & 0.338 & 0.246 & 1.402 & & -0.929 & 0.290 & 0.395 & \\
\hline \multicolumn{7}{|l|}{ Neonatal Parameters } & & \\
\hline Weight (g) & -0.001 & 0.011 & 0.999 & & -0.001 & 0.017 & 0.999 & \\
\hline Length (cm) & -0.104 & 0.226 & 0.901 & & -0.053 & 0.548 & 0.948 & \\
\hline Head circumference (cm) & 0.323 & 0.143 & 0.724 & & 0.229 & 0.246 & 1.256 & \\
\hline
\end{tabular}

Table 6 shows that birth weight could predict Apgar score of male and female birth. Maternal Waist circumference predicts Apgar score of male birth.

Table 7

Association result of Apgar score and mode of delivery of male and female neonates at Alex Ekwueme Federal University Teaching Hospital

\begin{tabular}{|c|c|c|c|c|c|c|}
\hline & Male & & & Female & & \\
\hline \multirow[t]{2}{*}{ Apgar Score } & \multicolumn{2}{|l|}{ Mode of Delivery } & \multirow[t]{2}{*}{$p$-value } & \multicolumn{2}{|l|}{ Mode of Delivery } & \multirow[t]{2}{*}{ p-value } \\
\hline & Spontaneous Vagina & Cesarean & & Spontaneous Vagina & Cesarean & \\
\hline Normal & $95.70 \%$ & $69.20 \%$ & \multirow[t]{2}{*}{0.001} & $95.10 \%$ & $58.30 \%$ & \multirow[t]{2}{*}{0.001} \\
\hline Abnormal & $4.30 \%$ & $30.80 \%$ & & $4.90 \%$ & $41.70 \%$ & \\
\hline
\end{tabular}

Table 7 shows significant association between Apgar score and mode of deliveries of male and female neonates $(P<0.05)$

Table 8

Correlation coefficients of Apgar score and duration of stages of labor of male and female neonates at Alex Ekwueme Federal University Teaching Hospital

\begin{tabular}{llc} 
Duration of stages of Labor & \multicolumn{2}{l}{ Apgar score } \\
\cline { 2 - 3 } & Male & Female \\
\hline First stage of labor & -0.178 & -0.049 \\
\hline Second stage of labor & -0.172 & $0.264^{\star}$
\end{tabular}

*indicate significant relationship $(P<0.05)$ 
Table 8 shows a significant relationship between duration of second stage of labor and Apgar score of female newborn $(p>0.05)$.

\section{Discussion}

The overwhelming religious and cultural supports for child birth through vagina in Africa boost morale of expectant mothers to endure pains associated with it instead of Caesarean birth. In our locality, the perception that duration of labor for a female birth should be longer than that of a male birth makes it difficult for gynecologists to convince an expectant mother to go for Caesarean birth, even when labor lasts longer than expected. The assertion is likened to the difference in time spent when a married couple makeup for an outing or a party. Alex Ekwueme Federal University Teaching Hospital Abakaliki is a foremost public tertiary health provider in Nigeria, which educates mothers on balanced diet, supplements and vaccines during antenatal visits. The hospital provides a general, referral and specialized clinical services including maternity, childcare, vesicovaginal fistula units, and adopts a consistent labor protocol. We attempt to develop a handy alternative means to complement existing protocol for term pregnancy investigations in the hospital, using anthropometric tools. We relied on accurate record of the experienced research assistants and midwives.

Similar to other studies done in Southern-Nigeria [21,28,29], Singapore [30], Tanzania [31], Dharan [32] and Indonesia [20], the values of birth weight were within the range of the mean values in our study; $3091.49 \pm 429.22 \mathrm{~g}, 3195.18 \pm 522.87 \mathrm{~g}$ and mostly normal (Table 1). According to past studies in Northern-Nigeria [33,34], gender difference exists in birth weight, which was attributed to dissimilarity in levels of nutrition, climate conditions and body stature of the population which was studied. Conversely, our study did not establish a significant mean difference in weight, length and head circumference for male and female birth. The reason could be attributed to the fact that the mothers were reliably educated on nutrition and supplements, and received routine vaccines and maternity care. Although, studies of Li and Chang [35] in Eastern Taiwan and Tayeh et al. [36] in Lebanon, and Ng et al. [37] in Kuwait, observed that birth weight increases as maternal age advances, the increments in birth weight with maternal age was limited to male birth. It also suggested that male birth weight and length were specifically dependent on maternal weight and BMI, and WHR, respectively (Table 2). Our findings were similar to that of Fukuda et al. [38,39], suggesting that maternal body stature at term pregnancy predispose male birth features.

Concerning the rate of Cesarean deliveries for male and female birth (Figure 1), it was low when compare to the result of Coelho et al [10], probably, due to the perception that it is for weak ladies in our locality and it is considered when spontaneous vaginal birth fails. Consequently, expectant mothers request for more time to "push" during labor, instead of cesarean delivery. In fact, the purpose of the study was to establish an evidence base on anthropometric approach to assist gynecologists convince expectant partners to go for Caesarean birth, and circumvent prolong labor and its associated problems. Comparing male and female birth, the results reveal that maternal WHR and birth weight and length could predict mode of delivery of male birth (Table 4). Similar to the results of Siggelkow et al. [40], it suggests that relatively large maternal waist and hip girths, birth weight and length could be risk factors of male birth through vagina. The prevalence of macrosomic male birth and large maternal WHR could contribute to Cephalopelvic disproportion, which has been a risk of spontaneous vaginal delivery [3]. Similar to the findings of Biratu et al. [14] and Ezemagu et al [3] male birth has a higher odd of Macrosomia. Fetal Macrosomia has been associated with labor augmentation with Oxytocin, failed instrumental delivery, wound complication, thrombosis, adverse reaction of anesthesia and Cesarean delivery $[4,33]$.

Cesarean delivery, complicated labor, premature birth and high risk pregnancy, could lead to abnormal Apgar score, and maternal sedation or anesthesia, congenital malformation, trauma and inter-observer variability could influence the assessment. Contrary to the result of Ehrenstein [41] and Hegyi et al., 1998, abnormal Apgar score was associated with relatively large birth weight and Cesarean birth (Table 6 \& 7). Conversely, the prevalence of abnormal Apgar score at 1 minute of birth among Cesarean deliveries was high (male $30.80 \%$, female $41.70 \%$ ). It could be as a result of prolonging labor or other labor complications which made spontaneous vaginal birth fail, necessitating the option of Cesarean birth. The reasons for option of Cesarean delivery in our locality as contained in the obstetrics and gynecology protocol of AEFUTHA were fetal distress, mal-presentation of fetus, Macrosomia, Cephalopelvic disproportion, uterine inertia, Placenta previa and Pre enclampsia. They were mostly attributed to poor handling of women in labor by birth attendants and late referral of complicated labor, access to conventional hospitals and cultural perceptions that Cesarean section is for a weak lady in Nigeria.

Regarding duration of labor, there was no significant mean difference between the duration of labor for sex (Table 1). Although, the variation in duration of first stage of labor for male birth did correlate with maternal weight and height (Table 2), none of the maternal or neonatal anthropometric features could predict the duration of first stage of labor for sex (Table 5). Similar to the result of Mihret-ab et al. [43], advanced maternal age and overweight increased the duration of second stage of labor for female birth. Similar to our Ezemagu

Page $10 / 14$ 
et al [3], abnormal Apgar score of male birth was attributed to prolong labor due to large maternal waist and fetal macrosomia at term pregnancy. Therefore, relatively young expectant mothers with normal BMI and WHR could be granted more time to "push" during second stage of labor, since it could enhance the Apgar score at 1 minute of birth in female neonates (Table 8).

\section{Conclusion}

The study reveals that maternal and male birth features tend to be similar, and relatively large maternal WHR at term pregnancy and fetal macrosomia could be risk factors of male birth through vagina. None of the maternal or neonatal anthropometric features could predict the duration of first stage of labor for male or female birth. Advance age of mothers in pregnancy and overweight and WHR could be responsible for prolong labor, especially, the second stage of labor for female birth. Furthermore, the study reveals that prolong labor leads to abnormal Apgar score but granting a closely monitored more time to "push" during second stage of labor enhances the score in female birth. Perhaps, resolving the above puzzle could explain the difference in duration of labor for female and male birth in our locality. The study provided a comprehensible means to enable the gynecologists and midwives envisage and advice expectant mothers on possible risk of birth through vagina, with respect to her baby's sex and her belief and cultural obligation in our locality.

\section{Declarations}

\section{Ethics approval and consent to participate}

The study was approved by the Research and Ethics Committee of AE-FUTHA, with a reference number: AEFUTHA/REC/VOL2/2019/213. Informed consent was obtained from all subjects who voluntarily signed the consent form. Methods adopted in this study was carried out in accordance with relevant guidelines and regulations

\section{Consent for Publication}

All participants gave their consent to publish their identifiable data in an online, open access journal.

\section{Data Availability}

The data were documented in gynecology ward of Alex Ekwueme Federal Teaching Hospital, Abakaliki, between $1^{\text {st }}$ July and $1^{\text {st }}$ December, 2019. The authors confirm that all data are fully available without restriction. The entire relevant data are within the manuscript.

\section{Competing Interest}

Not Applicable

\section{Funding}

Not Applicable

\section{Authors Contributions}

Conceptualization: EUK and UGC; Methodology: EFC, EUK, IOA, OO and POE; Statistical analysis: UGC, CU and RO; Data collection: EFC, RO, CU, POE and OO; Manuscript draft preparation: UGC, CU, RO, IOA and TE; Manuscript writing: UGC, EUK, POE and IOA; Review and editing: EUK, EFC and OO; Supervision: EUK, IOA and UGC. Approval to submit to your journal: All authors

\section{Acknowledgments}

We sincerely the midwives; Umezuruike Clementina clemez2014@gmail.com and Nwoke Easter okwudilichukwuesther@gmail.com and the women in labor that complied with the procedure and

participated fully in the study, 
despite the painful stress of labor.

\section{References}

1. Caesarean Sections in Nigeria - Thoughts, Belief Systems and Perceptions. Nigeria Health Watch, April 29, 2020.

2. Maryam Z, Robab LR, Effat MK. Vaginal Delivery vs. Cesarean Section: A Focused Ethnographic Study of Women's Perceptions in the North of Iran. Int J Community Based Nurs Midwifery. 2015; 3(1) 39 - 50

3. Ezemagu UK, Uzomba CG, Ubochi C, Ogbu R, Egba CF, Onuora O. Maternal and neonatal anthropometric analyses: determining birth outcomes in low risk pregnancies at Alex Ekwueme Federal University Teaching Hospital, Abakaliki. Int. J. Gynecol. Obstet Research https://doi.org/ 10.1002/IJG0.13527 January 2021

4. Wong PY, WKTo W. Risk factors and pregnancy outcomes of macrosomia: a retrospective cohort study. Hong Kong J Gynecol. Obstet. Midwifery, 2018; 18:18-23

5. Lumbanraja S, Lutan D, Usman I. Maternal weight gain and correlation with birth weight. Procedia - Social and Behavioral Sci. 2013; 103: 647-656.

6. Boulet S, Salihu H, Alexander GR. Mode of delivery and birth outcomes of macrosomic infants. J. Obstet. Gynecol. 2004; 24(6): 6229

7. World Health Organization. Who collaborative study. Maternal anthropometry and pregnancy outcomes. WHO Bulletin 1995,73

8. Satwanti K, Prerna B, Meenal D, Deepali V, Shilpi G, Mary G T. Maternal Predictors of Newborn Somatometrics. Journal of Anthropology, 2012; Article ID 639345, doi: 1155/2012/639345

9. Ashraf S, Rahman AJ, Abbas K. Anthropometric measurements; newborns in Urban Karachi population. Professional Med. J. 2012; 19(2): 150-154

10. Coelho KS, Souza Al, Batista FM. Avalicae antropometrica do estado nutricional da gestante: visae retrospective e prospective. Rev Brass Saudi Maternal Infant, 2002; 2:57-61

11. Guihard-Costaa AM, Grangéb G, Larrochec JC, Papiernikb E. Sexual differences in Anthropometric measurements in French Newborns. Biol. Neonat. 1997; 7 (2) :156-164

12. Khatun S, Rahman M. Quality of antenatal care and its dose-response relationship with birth weight in a maternal and child health training institute in Bangladesh. J. Biosoc. Sci. 2008; 40: 321-337

13. Kayode-Adedeji B, Egharevba O, Omoregbee H. Prevalence of fetal macrosomia and neonatal complications in a Nigerian suburban hospital: a 5 year study. J Pediatr Neonatal Individ. Med. 2018; 7: 070120

14. Biratu AK, Wakgari N, Jikamo B. Magnitude of fetal macrosomia and its associated factors at public health institutions of Hawassa city, Southern Ethiopia BMC Res. Notes 2018; 11:888

15. Oladapo OT, Souza JP, Fawole B, Mugerwa K, Perdona ÂG, Alves D, et al. Progression of the first stage of spontaneous labour: A prospective cohort study in two sub- Saharan African countries. PLoS Med. 2018 15(1):

e1002492. https://doi.org/10.1371/journal. pmed.1002492

16. Cunningham FG, Leveno KJ, Bloom SL, Hauth JC, Rouse DJ, Spong CY. Williams Obstetrics 23rd ed. New York: McGraw-Hill. 2010.

17. Nigeria Demographic and Health Survey 2018

18. World Health Organization-WHO, 2018. Obesity and Overweight. www.who.int/mediacenter/factsheets/fs311/en/>(acess: February 2018)

19. Pedersen JF. "Ultrasound evidence of sexual difference in fetal size in first trimester". Bri. Med. J. 1980; 281(6250): 1253

20. Jane M, Kusin A, De C. With birth weight distribution in a healthy urban population in Surabaya-Indonesia. Trop. Geograph. Med. 1989; 41:146-150.

21. Olutekunbi OA, Adaobi US, Idowu OS, Elizabeth AD, Olisamedua FN. Skinfold Thickness Measurement in Term Nigerian Neonates: Establishing Reference Values. International Journal of Pediatrics, Volume 2018, Article ID 3624548, 10 pages. https://doi.org/10.1155/2018/3624548

22. Goon DT, Toriola AL, Shaw BS, Akinyemi O. Estimating waist circumference from BMI in South African children. Sci. Res. and Essays. 2011; 6(15): 3104-3108

23. Tasdemir D, Karaman E, Yildiz A, Han A, Karaman Y, Talay H. The effect of obesity on maternal and fetal outcomes in term pregnant women: a case control study. Istanbul Kanuni Sultan Suleyman Med. J. 2015; 7:73-78

Page $12 / 14$ 
24. Ejike CECC, Ije I. Obesity in young-adult Nigerians: Variations in prevalence determined by anthropometry and bioelectrical impedance analysis, and the development of percentage body fat prediction equations. Int. Arch. Med. 2012; 22(5) 2-7.

25. Michelle GS, Alan MB, Costas T, Zoe HR, Karen H. Prediction of whole-body fat percentage and visceral adipose tissue mass from five anthropometric variables. Plos One, 2017; 12(5): 234-239

26. Rustagi N, Prasuna J, Taneja DK. Anthropometric Surrogates for Screening of Low birth weight Newborn: A community-based study. Asia Pacific J. Public Health, 2011; 24(2):343-51

27. Sajjadian N, Shajari H, Rahimi F, Jahadi R, Barakai MG. Anthropometric measurements at birth as predictor of low birth weight. Health, 2011; 3(12): 752-756

28. Ugwa EA. Maternal anthropometric characteristics as determinants of birth weight in North-West, Nigeria: A prospective stud. Nig. J. Basic Clinical Sci. 2014; 11:8-12

29. Shittu AS, Kuti O, Orji EO, Mkinde NO, Ogunniyi SO, Ayoola 00 et al. Clinical versus sonographic estimation of weight in South West Nigeria. J. Health Popul. Nutri. 2007; 25:14-23

30. Cheng MC, Chew PC, Ratman SS. Birth weight distribution of Singapore Chinese, Malay and Indian infants from 34 weeks to 42 weeks gestation. J. Obstet. Gynaecol. Bri. Commonwealth, 1972; 79:149-53

31. Mosha TDE, Philemon N. Factors Influencing Pregnancy Outcomes in Morogoro Municipality, Tanzania. Tanzania J. Health Res. 2010; 12(4):249-260

32. Mohanty C, Prasad R, Srikanth AR, Ghosh JK, Singh TB, Das BK. Maternal anthropometry as predictors of low birth weight. J. Trop. Pediat. 2006; 52:24-29

33. Mutihir JT, Pam SD. Anthropometric and Other Assessment Indices of the Newborn in Jos, Nigeria. Annals Afri. Med. 2006; 5(4) 2006: $192-196$

34. Osuhor PC. Birth weights in Katsina, northern Nigeria. J. Trop. Paediat. 1986; 32: 200-202

35. Li YM, Chang TK. Maternal demographic and psychological factors associated with low birth weight in Eastern Taiwan. Kaohsiung J. Med. Sci. 2005; 502-510

36. Tayeh GA, Tatiana P, Inaam H, Christelle Y, Alexandra B. Effect of weight gain during pregnancy on anthropometric measures of the newborn and gestational and neonatal complications: retrospective study on 1,000 Lebanese women admitted at Hôtel-Dieu de France university hospital. Obst. \& Gyne. Int. J. 2019; 10(2):72-78

37. Ng SK, Olog A, Spinks AB, Cameron CM, Searle J, McClure RJ. Risk factors and obstetric complications of large for gestational age births with adjustments for community effects: results from a new cohort study. BMC Public Health. 2010; 10: 460.

38. Fakuda S, Tanaka Y, Harada K, Saruwatari A, Kitaoka K, Odani K, Higashi A et al. Maternal Body Mass Index Correlates with the Neonatal Physique of Male Infants. Tohoku J Exp Med. 2015; 237(1): 69-75

39. Fakuda S, Tanaka Y, Harada K, Saruwatari A, Kitaoka K, Odani K, Higashi A et al. Male Infants Born to older Pregnant Women are Affected by Maternal Physique at the beginning of the Pregnancy through Birth until 18 Months of Age. J Nutr Sc Vitaminol (Tokyo). 2019; 65(2) : 123-131

40. Siggelkow W, Boehm D, Skala C, Grosslercher M, Schmidt M et al. The influence of macrosomia on the duration of labor, the mode of delivery and intrapartum complications Arch Gynecol Obstet. 2008; 278(6): 547-53

41. Ehrenstein V. Association of Apgar scores with death and neurologic disability Clin Epidemiol. 2009; 1: 45-53.

42. Hegyi T, Carbone T, Anwar M, Ostfeld B, Hiatt M, Koons A, Pinto-Martin J, Paneth N. The apgar score and its components in the preterm infant. Pediatrics, 1998; 101(1):7

43. Mihret-ab Mehari, Hayat Maeruf, Henok Kumsa et al., 2020 Advanced maternal age pregnancy and its adverse obstetrical and perinatal outcomes in Ayder comprehensive specialized hospital, Northern Ethopia, 2017: a comparative cross-sectional study BMC Pregnancy and Childbirth 2020; 20(60) https://doi.org/10:1186/s12884-020-2740-6

\section{Figures}




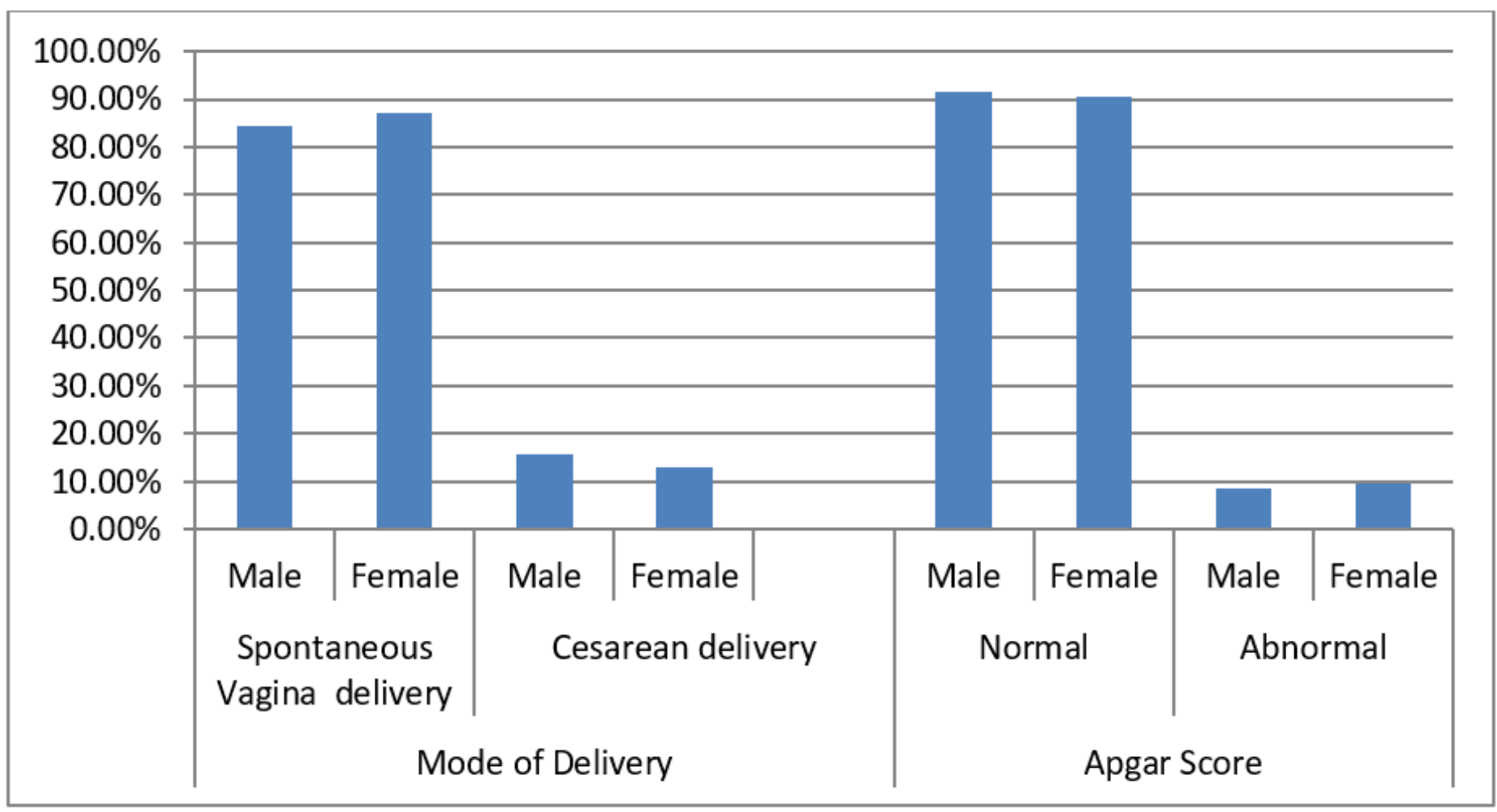

Figure 1

Frequency distribution for mode of delivery (male; spontaneous $84.34 \%$, C/S 15.66\%), (female; spontaneous $87.24 \%$, C/S 12.76\%) and Apgar score (normal; male 95.70\%; female 95.10\%), (abnormal; male 4.30\% female 4.90\%) at Alex Ekwueme Federal University Teaching Hospital, Abakaliki. 